\title{
When the patients stayed home: the impact of the COVID-19 pandemic on acute cardiac admissions and cardiac mortality in Malta
}

\author{
Neil Grech ${ }^{1}$ (D) $\cdot$ Rachel Xuereb ${ }^{1} \cdot$ Kathleen England ${ }^{2} \cdot$ Robert G. Xuereb $^{1} \cdot$ Maryanne Caruana $^{1,3}$ (D) \\ Received: 6 August 2020 / Accepted: 15 March 2021 / Published online: 23 March 2021 \\ (C) The Author(s), under exclusive licence to Springer-Verlag GmbH Germany, part of Springer Nature 2021
}

\begin{abstract}
Aim This study aimed to investigate the impact of severe acute respiratory syndrome coronavirus 2 (SARS-CoV-2) infection on all types of acute cardiac admissions (ACAs) and cardiac mortality in Malta.

Methods Number, characteristics and delay to presentation of ACAs to our institution during the study period (28 February-30 April 2020) were compared with the corresponding 2019 period. Non-parametric correlation analyses between daily SARSCoV-2 cases in Malta, Italy and the UK and daily ACAs were performed. Differences in cardiac death distribution (community vs. in-hospital) during the two periods were analysed.

Results There was a significant decline in daily ACAs in 2020 (median 3 [IQR 3]) vs. 2019 (median 5 [IQR 4]), $p<0.001$. Patient characteristics were comparable. Delay to presentation for 2020 ACAs was significantly higher across all categories (ST-elevation myocardial infarction [STEMI] median: 2019 [1 h, IQR 1] vs. 2020 [4 h, IQR 43.8], $p=0.009$; non-ST-elevation-acute coronary syndrome [NSTE-ACS] median: 2019 [4 h, IQR 71] vs. 2020 [48 h, IQR 199], $p=0.001$; non-ACS median: 2019 [24 h, IQR 95] vs. 2020 [84 h, IQR 499.8], $p<0.001$ ). There was a significant negative correlation between ACAs and daily Malta SARS-CoV-2 infection cases $\left(r_{s}=\right.$ $-0.298, p=0.018$ ) but not with cases in Italy and the UK when controlling for Malta cases. Significantly more cardiac deaths occurred in the community in $2020(107,61.8 \%)$ compared to $2019(87,46.8 \%)(p=0.004)$.

Conclusion Fear of SARS-CoV-2 infection led to a significant avoidance of acute cardiac care with an accompanying rise in community cardiac deaths, suggesting a need for better public education on recognising and addressing cardiovascular symptoms.
\end{abstract}

Keywords COVID-19 $\cdot$ SARS-CoV-2 $\cdot$ Acute coronary syndrome $\cdot$ Heart failure $\cdot$ Mortality

\section{Introduction}

The worldwide spread of the novel severe acute respiratory syndrome coronavirus 2 (SARS-CoV-2) responsible for coronavirus disease 2019 (COVID-19) has led to a large-scale public health emergency. Healthcare systems implemented a number of containment measures to restrain the spread of

Maryanne Caruana

maryanne.caruana@um.edu.mt

1 Critical Coronary Care Unit, Department of Cardiology, Mater Dei Hospital, Msida, Triq id-Donaturi tad-Demm, Malta

2 Malta National Mortality Registry, Directorate for Health Information \& Research, Pieta, Malta

3 Department of Medicine, Faculty of Medicine \& Surgery, University of Malta, Msida, Malta
SARS-CoV-2, and hospitals underwent major restructuring over short periods of time to increase their capacity to treat patients with COVID-19 whilst retaining their ability to deal with other acute conditions (Ahn et al. 2020). As a consequence, a number of documents were issued over the past months to help guide caregivers with acute cardiac care provision during these extraordinary times (European Society of Cardiology 2020a; Mahmud et al. 2020a; Welt et al. 2020). Despite these efforts, a decline in patient admissions for the management of acute cardiac conditions and a concomitant increase in delay to presentation started being reported, with the vast majority of such studies concentrating on acute coronary syndrome (ACS) admissions (De Filippo et al. 2020; Frankie et al. 2020; Garcia et al. 2020; Metzler et al. 2020; Moroni et al. 2020; PessoaAmorim et al. 2020; Rodríguez-Leor et al. 2020; Solomon et al. 2020; Tsioufis et al. 2020). 
Malta is a small archipelago in Southern Europe with a population of approximately 490,000 , and a member of the European Union since 2004 (National Statistics Office 2019). Its healthcare system is funded through taxation and national insurance and is free at point of care. All specialised services, including acute and long-term cardiology care, primary percutaneous coronary interventions (PPCI), as well as intensive care, are provided in a single centre (Mater Dei Hospital $(\mathrm{MDH})$ ), located in central Malta. The first case of COVID19 in Malta was reported on 7 March 2020. Several measures to contain the spread of SARS-CoV-2, including closure of the airport and seaport and closure of non-essential and entertainment outlets, schools and universities, were deployed gradually over the subsequent weeks, though a total lockdown was never imposed. The public was updated about the number of COVID-19 cases and recoveries through a daily televised press conference led by the Superintendent of Public Health and was able to seek expert advice through a COVID-19 freephone helpline. By 31 May 2020, there were a total of 618 cases of SARS-CoV-2 infection and 9 SARS-CoV-2related deaths (Buttigieg 2020).

As of mid-March 2020, the majority of non-urgent investigations, surgeries and interventions in $\mathrm{MDH}$ were temporarily suspended until mid-May, when a transition phase with gradual reinstitution of services was implemented. Management of patients presenting to the Emergency Department (ED) was carried out in two separate sections depending on likelihood or otherwise of SARS-CoV-2related illness at triage. Similarly, in-patient management of patients with a positive SARS-CoV-2 swab was undertaken in separate wards from those who tested negative and cross-over of healthcare staff between wards was kept to a minimum to avoid in-hospital viral spread. The Department of Cardiology continued to provide all emergency services and no staff redeployment to other clinical areas was required.

This study is the first to report the nationwide Maltese experience of the COVID-19-related impact on acute cardiac admissions (ACAs) and, to the best of the authors' knowledge, is also one of the first in the literature to include all forms of acute cardiac pathologies in its analyses. The main aims were to (a) quantify the decline in, and any associated delays in presentation for, all ACAs during the initial wave of the COVID-19 pandemic in Malta, (b) investigate the potential correlation of ACAs with numbers of daily reported SARS-CoV-2 cases in Malta and other European countries, and (c) determine the initial impact of ACA trends on cardiac mortality.

\section{Methods}

The study cohort consisted of all ACAs recorded during the nine-week period of 28 February through till 30 April 2020.
The control cohort used for comparison analyses consisted of all recorded ACAs during the corresponding calendar period in 2019 (27 February-30 April 2019). Hospital admission data was collected retrospectively from MDH's electronic patient management and discharge summary databases. Cardiac mortality data was obtained from the Malta National Mortality Registry maintained by the Directorate of Health Information and Research. Data on number of daily SARSCoV-2 cases in Malta was obtained from the official online dashboard maintained by the COVID-19 Public Health Response Team (Buttigieg 2020), while data on number of infection cases in Italy and the United Kingdom (UK) were obtained from an open-access real-time statistics website (Worldometer 2020). Following institutional data protection clearance, the study was approved by the University of Malta Research Ethics Committee, in compliance with the ethical guidelines of the 1975 Declaration of Helsinki and was performed with a waiver of consent.

ACA was defined as an unplanned admission of an adult subject (aged $\geq 16$ years) under the care of the MDH cardiology team for the management of acute cardiac pathology, and included all admissions through MDH ED, direct admissions from cardiology outpatient clinics and emergency inpatient transfers from the regional hospital on the sister island of Gozo. During some sub-analyses, ACAs were divided into two broad categories: ACS and non-ACS. ACS was used to refer to all forms of acute coronary events, including ST segment elevation myocardial infarction (STEMI) and non-ST segment elevation ACS (NSTE-ACS) with or without biomarker rise. Non-ACS ACAs referred to all other admissions not directly related to an acute coronary event and included heart failure, valvular disease, arrhythmias and myocardial or pericardial disease. Delay in presentation referred to the lag in hours between onset of symptoms and medical contact for assessment. Past cardiac history was defined as any known cardiac condition under treatment and/or follow-up or any previous cardiology contact or admission. Cardiac death was defined as death from any cardiac cause as declared on the death certificate or confirmed at post-mortem studies. Community deaths referred to those occurring outside an acute hospital setting.

In a first analysis, the decline in ACAs was quantified by comparing daily ACA rates between study and control periods, with sub-analyses investigating (a) differences in patient characteristics (age, gender, past cardiac history and ACA category) and (b) delay in presentation between the two cohorts. A second analysis investigated the potential correlation between daily reported new SARS-CoV-2 infected cases in Malta, Italy (due to geographical proximity) and the UK (due to historical ties) and daily ACAs during the 2020 study period. A final analysis investigated differences in trends in cardiac mortality (community vs. in-hospital) between the admission periods in 2019 and 2020. 
Categorical variables were analysed using the chi-square test. Fisher's exact test was applied in the case of smaller sample sizes. Comparison of all continuous variables was performed using the Mann-Whitney U test after Shapiro-Wilk test established a non-normal distribution for all. Separate Spearman's correlation analyses were applied to study the potential relationship between daily new SARS-CoV-2 cases in (a) Malta, (b) Italy and (c) the UK and daily ACAs in our institution. Subsequently, non-parametric partial correlations were used to analyse the relationship between ACAs and SARS-CoV-2 cases in Italy and the UK while controlling for cases in Malta. All analyses were performed using SPSS 26 (IBM SPSS 26, IBM Corp., Armonk, NY). Statistical significance was defined as $p<0.05$.

\section{Results}

There were 234 ACAs out of a total of 3484 medical admissions $(6.7 \%)$ during the study period compared to 363 ACAs out of 5473 medical admissions $(6.6 \%)$ during the corresponding period in $2019(p=0.869)$, with significantly lower daily numbers of ACAs in 2020 (median 3 [IQR 3]) when compared to 2019 (median 5 [IQR 4]) $(p<0.001)$ (Fig. 1). A timeline of ACA trends over the 9-week study period is shown in Fig. 2. Data on delay in presentation was available for $172 / 234$ patients in the study cohort and $256 / 363$ patients in the control cohort. Comparison of these timeframes demonstrated a significantly longer delay in presentation across all ACA categories in 2020 (STEMI median: 2019 [1 h, IQR 1] vs. 2020 [4 h, IQR 43.8], $p=0.009$; NSTE-ACS median: 2019 [4 h, IQR 71] vs. 2020 [48 h, IQR 199], $p=0.001$; non-ACS median: 2019 [24 h, IQR 95] vs. 2020 [84 h, IQR 499.8], $p<0.001)$. There were no significant differences in patient characteristics in both cohorts (Table 1).

There was a statistically significant negative correlation between ACAs and daily reported new SARS-CoV-2 infection cases in Malta $\left(r_{s}=-0.298, p=0.018\right)$. On initial analysis, a significant negative correlation was also demonstrated between ACAs in our institution and daily reported new SARS-CoV-2 case numbers in Italy $\left(\mathrm{r}_{\mathrm{s}}=-0.347, p=0.005\right)$ and the UK $\left(r_{s}=0.322, p=0.01\right)$. However, the latter correlations were not found to be statistically significant upon controlling for Maltese new infection cases (Italy cases controlling for Malta cases $r=-0.203, p=0.114$; UK cases controlling for Malta cases $r=-0.175, p=0.174$ ).

There was a higher daily community cardiac death rate during the 2020 study period (daily median 2 deaths [IQR 1]) compared to the 2019 control period (daily median 1 death [IQR 1]), although this difference failed to reach statistical significance $(p=0.075)$. However, a statistically significant shift in the distribution of cardiac deaths was observed when study and control periods were compared, with community deaths representing a significantly higher proportion of all cardiac deaths in $2020(107 / 173,61.8 \%)$ when compared to $2019(87 / 186,46.8 \%)(p=0.004)$ (Fig. 3).

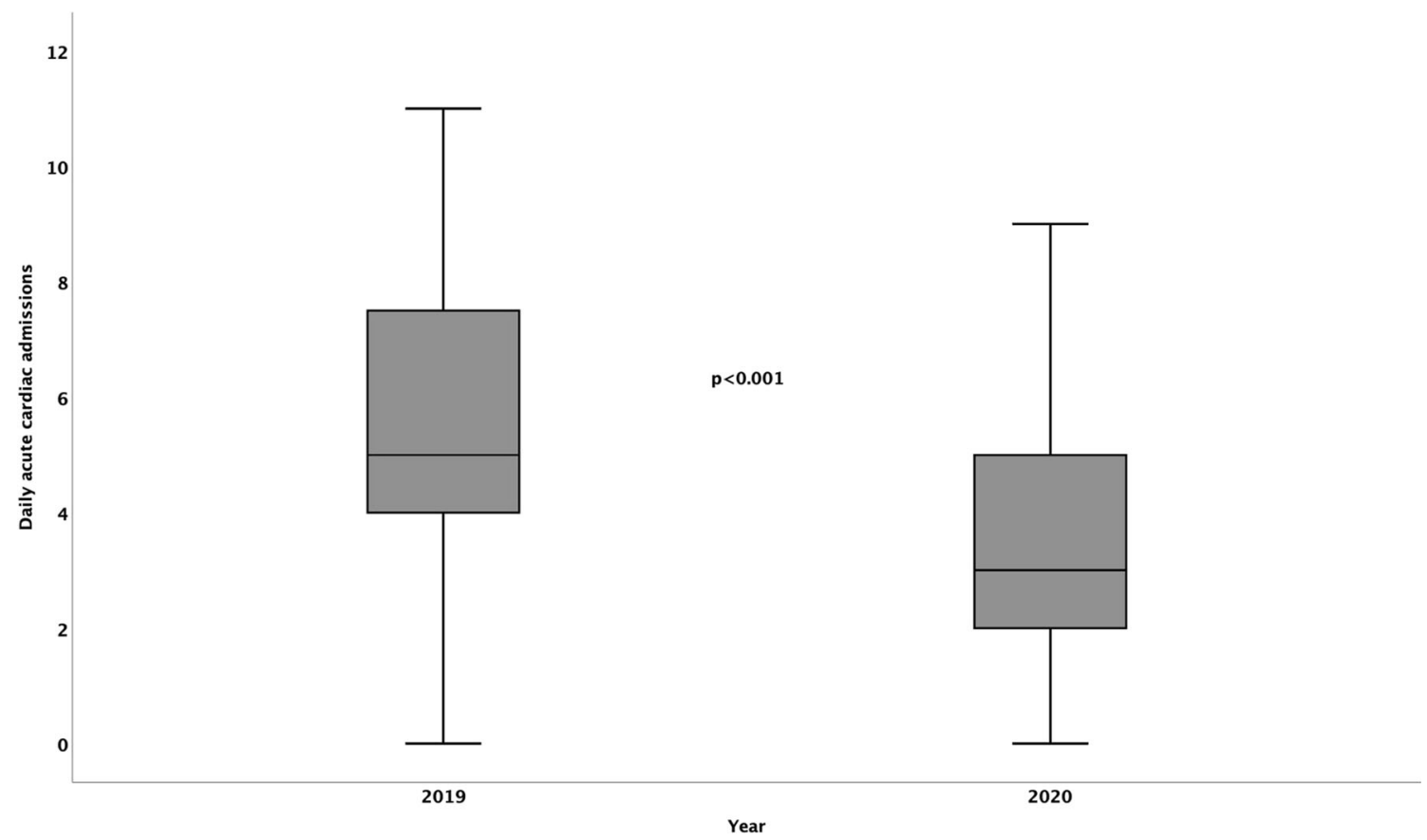

Fig. 1 Comparison of daily acute cardiac admissions during the study (2020) and control (2019) periods. There was a significantly lower number of daily admissions during the study period (median 3 [IQR 3]) compared to the control period (median 5 [IQR 4]) $(p<0.001)$ 


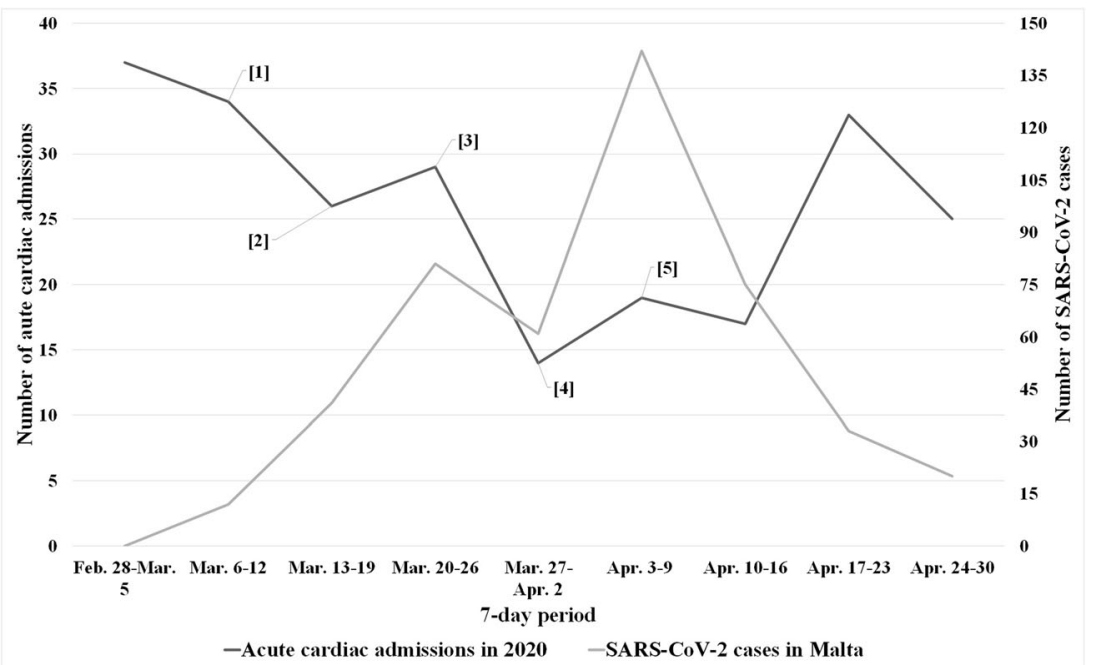

Fig. 2 Trend in acute cardiac admissions during the 9-week study period in 2020. There was a gradual decline in the number of weekly acute cardiac admissions which declined furthest during the last week of March and first week of April 2020. This coincided with increasing numbers of reported SARS-CoV-2 cases and tightening of restrictions aimed at limiting viral transmission. Landmark points along 2020 timeline [1] First reported SARS-CoV-2 case in Malta (7 March), COVID-19 declared a pandemic by World Health Organisation (11 March) and partial travel ban from selected high-risk countries issued (11 March); [2]

\section{Discussion}

During the first half of 2020, several centres across all continents reported a rapid decline in cardiac admissions and marked increases in delayed presentation rates coinciding with the occurrence and subsequent transmission of SARS-CoV-2 infections in their communities, with the vast majority of publications concentrating on STEMI and NSTE-ACS (Rodríguez-Leor et al. 2020; Garcia et al. 2020; Metzler et al. 2020; De Filippo et al. 2020; Tsioufis et al. 2020; Solomon et al. 2020; Pessoa-Amorim et al. 2020; Frankie et al. 2020; Moroni et al. 2020). These findings were mirrored in the current study on the response of the Maltese population to the COVID-19 pandemic with respect to all forms of ACAs (Fig. 2). On the one hand, it could be argued that the observed

Table 1 Comparison of patient characteristics in study and control cohorts

\begin{tabular}{lcll}
\hline Characteristic compared & 2019 & 2020 & $p$ \\
\hline Male gender (n [\%]) & $262(72.2)$ & $173(73.9)$ & 0.706 \\
Age (years) (median [IQR]) & $69.0(16)$ & $67.5(17)$ & 0.099 \\
ACS admission (n [\%]) & $142(39.1)$ & $107(45.7)$ & 0.126 \\
Past cardiac history (n [\%]) & $224(61.7)$ & $134(57.3)$ & 0.305 \\
\hline
\end{tabular}

There were no significant differences in patient characteristics between the two cohorts

(ACS = acute coronary syndrome)
Closure of education facilities (13 March), compulsory self-quarantine for all returning travellers (13 March) and closure of entertainment outlets, bars and restaurants (16 March); [3] Closure of all ports of entry into Malta (21 March) and closure of non-essential retail outlets (23 March); [4] People over 65 years of age and those with chronic disease advised to remain indoors (27th March) and COVID-19 declared as a public health emergency (1 April); [5] Peak of daily reported SARS-CoV-2 cases in Malta (52 cases) (7 April), first COVID-19-related death recorded in Malta (8 April) and Mater Dei Hospital patient visits suspended (9 April)

decline in ACAs reflects a reduction in the incidence of acute cardiac events brought about by factors such as the reduction in air pollution (Muhammad et al. 2020), less psychological stress (stemming from reduced work commutes and school runs) and a decline in tobacco smoking owing to the awareness raised about its detrimental effect on COVID-19 outcomes (Komiyama and Hasegawa 2020). That being said, it is the authors' opinion that the more likely explanation for this phenomenon is that of a generalised avoidance of hospital medical care by Maltese patients despite cardiac symptoms, driven primarily by fear of COVID-19 exposure.

Firstly, the negative economic impact of COVID-19 leading to job redundancies, and increasing unemployment and the sudden change in day-to-day routine for those asked to work from home, are likely to have acted as a source of heightened psychological and emotional stress. A Maltese study from 2008/2009 had demonstrated an increased incidence of acute coronary events as a consequence of heightened stress levels in the context of a national general election (Sammut 2011). Thus, it is reasonable to expect the recent national climate to translate into a similar effect on incidence of cardiac events. Secondly, reduced physical activity and overeating resulting indirectly from partial lockdown measures employed in the country could easily have had negative metabolic effects, which could further contribute to an increase in cardiovascular risk (Martinez-Ferran et al. 2020). Furthermore, COVID-19 could itself have contributed to an additional number of cardiac events through various pathophysiological 
mechanisms (Böhm et al. 2020; Clerkin et al. 2020; Kwong et al. 2018; Tavazzi et al. 2020; Zhou et al. 2020). Several findings in this study further support the theory of medical care avoidance of our cardiac patients. The decline in ACAs in our centre was not an isolated phenomenon as all forms of acute medical admissions experienced a comparable reduction during the same period, in line with what has been reported by other centres (Kansagra et al. 2020; Mahmud et al. 2020b). The concomitant marked delay in presentation for those patients that chose to seek assistance for their symptoms is also likely to represent a generalised reluctance to come to hospital.

Recent surveys confirmed a general feeling of fear of getting infected with SARS-CoV-2, especially in the light of the uncertainty of outcomes and the potential for high morbidity and mortality depicted in the media (Onest 2020; Saad 2020). Through direct questioning, the authors of an Italian caseseries confirmed fear of contracting the infection from the hospital setting as the reason for the delayed presentation of their patients (Moroni et al. 2020). Fear is a well-recognised driver of medical care avoidance behaviour (Kannan and Veazie 2014), though it is more commonly a fear of a serious diagnosis rather than one of contracting an illness. That being said, avoidance behaviour has previously been documented in reaction to large-scale infection outbreaks such as the H1N1 pandemic (Lau et al. 2010). In the current study, both the way in which ACA numbers decreased in line with the stepwise escalation in public health measures (Fig. 2) and the significant correlation between daily ACAs and local SARS-CoV-2 infection numbers further support the argument of fear being the main reason for the medical care avoidance observed in our population.

Pre-hospital delay in presentation of acute cardiac events, particularly acute myocardial infarction, is a well-known phenomenon, with female gender and older age being among the more consistent predictors of delay (Nguyen et al. 2010). Analysis of the admission characteristics (Table 1) demonstrates that all categories of Maltese patients with acute cardiac symptoms held back from addressing their complaints. Unfortunately, this included patients with a known cardiac history that would intuitively be expected to be better empowered to recognise and address worrying symptoms. Interestingly, while all ACA categories recorded significant delays in presentation, the delay was most marked for patients without ACS-suggestive symptoms, raising the possibility that chest pain is a symptom that patients take more seriously than others.

Delays in presentation can translate into increased morbidity and mortality (Alnsasra et al. 2017). While the extent of the implications of this nationwide decline in cardiac admissions and increased delay in presentations will only be fully appreciated in the longer term, our initial findings have already demonstrated a significant excess of community cardiac deaths (Fig. 3). As already hinted to by other authors (Baldi et al. 2020), it is reasonable to postulate that at least a number of these deaths were the consequence of early complications of acute cardiac events that could have potentially been avoided had there been no pre-hospital delay.

The low numbers reported in this study are a limitation, although they are the inevitable consequence of the small size of the Maltese population. To compensate for this, the number of patient subgroups used for the purposes of sub-analyses was restricted to avoid reducing the numbers further. Owing to the retrospective nature of this study, data on delay to presentation depended entirely on appropriate documentation at time of admission and was not available for all patients.
Fig. 3 Distribution of cardiac deaths during study and control periods. There was a significant difference in distribution of cardiac deaths with a significantly higher proportion of community deaths occurring during the 2020 study period

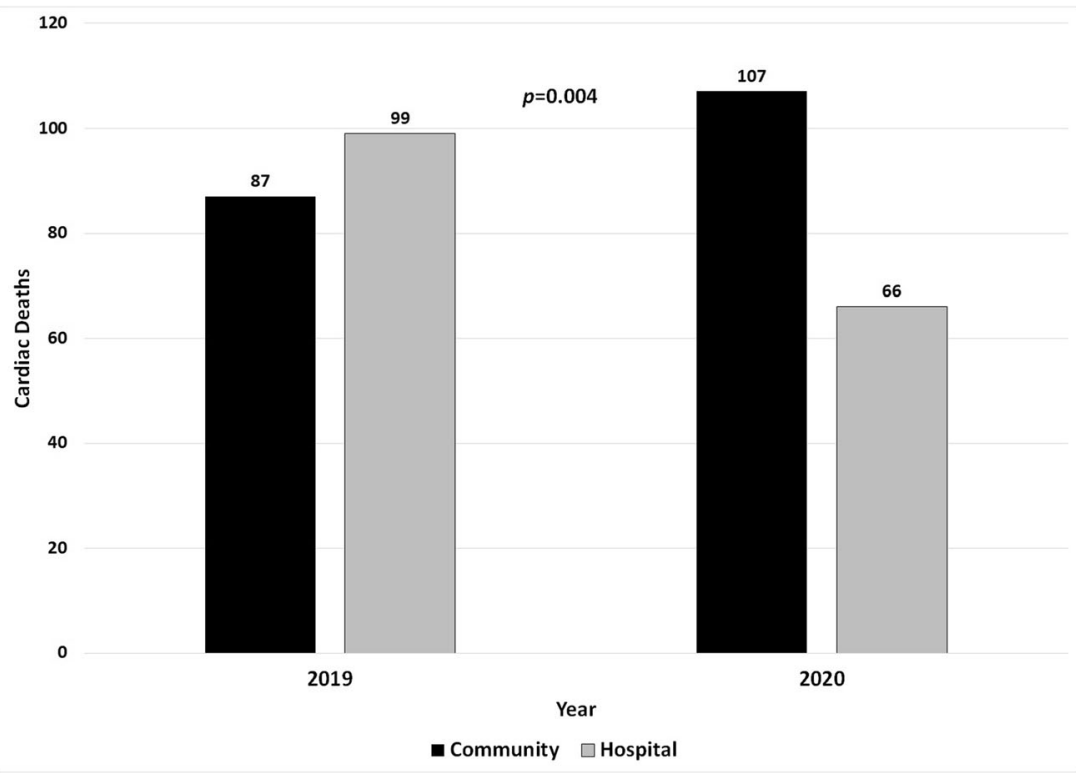




\section{Conclusions}

Avoidance of acute medical care through fear of contracting SARS-CoV-2 infection from the hospital setting resulted in a significant decline in all types of ACAs, prolonged delays in presentation and a rise in community cardiac deaths during the first two months of the COVID-19 pandemic in Malta. Longer-term studies into the impact of these trends on cardiac outcomes should provide a better understanding of the extent of 'collateral damage' resulting from the first wave of this viral pandemic. Better education of the general public, as well as patients with a background of cardiac disease (Dracup et al. 1997; Walsh et al. 2004), is warranted to avoid this phenomenon from repeating itself. This could be achieved through country-specific campaigns that relay the appeals made by international bodies (American College of Cardiology 2020; European Society of Cardiology 2020b).

Acknowledgements The authors would like to thank Dr. Sandra Di Stefano and Mr. David Borg from the Clinical Performance Unit at Mater Dei Hospital, Malta, for helping with patient admission data retrieval.

Author contributions NG contributed to conception, design, acquisition of data, analysis and interpretation of data, and drafting of the manuscript.

$\mathrm{RX}$ contributed to acquisition of data and revision of the manuscript.

$\mathrm{KE}$ contributed to conception, design, acquisition of data and revision of the manuscript.

RGX contributed to conception and revision of the manuscript.

$\mathrm{MC}$ contributed to conception, design, analysis and interpretation of data and drafting and critically revising the manuscript.

All authors read and approved the final manuscript, and all authors agree to be accountable for all aspects of the work in ensuring that questions related to the accuracy or integrity of any part of the work are appropriately investigated and resolved.

Funding The authors did not receive support from any organization for the submitted work.

Availability of data and material All data generated or analysed during this study are included in the article.

\section{Declarations}

Ethics approval This study was performed in line with the principles of the Declaration of Helsinki. Approval was granted by the University of Malta Research Ethics Committee (FRECMDS 1920 163). Consent was waived in view of the retrospective nature of the study.

Consent to participate Not applicable.

Consent for publication Not applicable.

Conflict of interest The authors declare that they have no conflict of interest.

\section{References}

Ahn DG, Shin HJ, Kim MH, Lee S, Kim HS, Myoung J, Kim BT, Kim SJ (2020) Current status of epidemiology, diagnosis, therapeutics, and vaccines for novel coronavirus disease 2019 (COVID-19). J Microbiol Biotechnol 30:313-324. https://doi.org/10.4014/jmb. 2003.03011

Alnsasra H, Zahger D, Geva D, Matetzky S, Beigel R, Iakobishvili Z, Alcalai R, Atar S, Shimony A (2017) Contemporary determinants of delayed benchmark timelines in acute myocardial infarction in men and women. Am J Cardiol 120:1715-1719. https://doi.org/10.1016/ j.amjcard.2017.07.085

American College of Cardiology (2020) American College of Cardiology urges heart attack, stroke patients to seek medical help. American College of Cardiology. https://www.acc.org/about-acc/pressreleases/2020/04/14/10/17/american-college-of-cardiology-urgesheart-attack-stroke-patients-to-seek-medical-help. Accessed 10 May 2020

Baldi E, Sechi G, Mare C, Canevari F, Brancaglione A, Primi R, Klersy C, Palo A, Contri E (2020) Out-of-hospital cardiac arrest during the Covid-19 outbreak in Italy. N Engl J Med 383:496-498. https://doi. org/10.1056/NEJMc2010418

Böhm M, Frey N, Giannitsis E, Sliwa K, Zeiher AM (2020) Coronavirus disease 2019 (COVID-19) and its implications for cardiovascular care: expert document from the German cardiac society and the world heart federation. Clin Res Cardiol 109:1446-1459. https:// doi.org/10.1007/s00392-020-01656-3

Buttigieg S (2020) COVID19-Malta/COVID19-Cases. GitHub. https:// github.com/COVID19-Malta/COVID19-Cases. Accessed 12 Jun 2020

Clerkin KJ, Fried JA, Raikhelkar J, Sayer G, Griffin JM, Masoumi A, Jain SS, Burkhoff D, Kumaraiah D, Rabbani L, Schwartz A, Uriel N (2020) COVID-19 and cardiovascular disease. Circulation 141:1648-1655. https://doi.org/10.1161/CIRCULATIONAHA.120.046941

De Filippo O, D'Ascenzo F, Angelini F, Bocchino PP, Conrotto F, Saglietto A, Secco GG, Campo G, Gallone G, Verardi R, Gaido L, Iannaccone $\mathrm{M}$, Galvani $\mathrm{M}$, Ugo F, Barbero U, Infantino V, Olivotti L, Mennuni M, Gili S, Infusino F, Vercellino M, Zucchetti O, Casella G, Giammaria M, Boccuzzi G, Tolomeo P, Doronzo B, Senatore G, Grosso Marra W, Rognoni A, Trabattoni D, Franchin L, Borin A, Bruno F, Galluzzo A, Gambino A, Nicolino A, Truffa Giachet A, Sardella G, Fedele F, Monticone S, Montefusco A, Omedè P, Pennone M, Patti G, Mancone M, De Ferrari GM (2020) Reduced rate of hospital admissions for ACS during Covid-19 outbreak in northern Italy. N Engl J Med 383:88-89. https://doi.org/10.1056/NEJMc2009166

Dracup K, Alonzo AA, Atkins JM, Bennett NM, Braslow A, Clark LT, Eisenberg M, Ferdinand KC, Frye R, Green L, Hill MN, Kennedy JW, Kline-Rogers E, Moser DK, Ornato JP, Pitt B, Scott JD, Selker HP, Silva SJ, Thies W, Weaver WD, Wenger NK, White SK (1997) The physician's role in minimizing prehospital delay in patients at high risk for acute myocardial infarction: recommendations from the National Heart Attack Alert Program. Working group on educational strategies to prevent prehospital delay in patients at high risk for acute myocardial infarction. Ann Intern Med 126:645-651. https:// doi.org/10.7326/0003-4819-126-8-199704150-00010

European Society of Cardiology (2020a) ESC guidance for the diagnosis and management of $\mathrm{CV}$ disease during the COVID-19 pandemic. https://www.escardio.org/Education/COVID-19-and-Cardiology/ ESC-COVID-19-Guidance. Accessed 10 May 2020

European Society of Cardiology (2020b) Appeals to "stay at home" during COVID-19 do not apply to heart attacks. https://www.escardio. org/The-ESC/Press-Office/Press-releases/Appeals-to-stay-at-homeduring-COVID-19-do-not-apply-to-heart-attacks-bis. Accessed 11 May 2020 
Frankie TCC, Kent-Shek C, Simon L, Anthony W, Arthur Y, Michael S, Yui-Ming L, Carmen C, Tat-Chi T, Matthew T, Hung-Fat T, Chung-Wah S (2020) Impact of coronavirus disease 2019 (COVID-19) outbreak on ST-segment-elevation myocardial infarction Care in Hong Kong, China. Circ Cardiovasc Qual Outcomes 13:e06631. https://doi.org/10.1161/CIRCOUTCOMES.120. 006631

Garcia S, Albaghdadi MS, Meraj PM, Schmidt C, Garberich R, Jaffer FA, Dixon S, Rade JJ, Tannenbaum M, Chambers J, Huang PP, Henry TD (2020) Reduction in ST-segment elevation cardiac catheterization laboratory activations in the United States during COVID-19 pandemic. J Am Coll Cardiol 75:2871-2872. https://doi.org/10. 1016/j.jacc.2020.04.011

Kannan VD, Veazie PJ (2014) Predictors of avoiding medical care and reasons for avoidance behavior. Med Care 52:336-345. https://doi. org/10.1097/MLR.0000000000000100

Kansagra AP, Goyal MS, Hamilton S, Albers GW (2020) Collateral effect of Covid-19 on stroke evaluation in the United States. N Engl J Med 383:400-401. https://doi.org/10.1056/NEJMc2014816

Komiyama M, Hasegawa K (2020) Smoking cessation as a public health measure to limit the coronavirus disease 2019 pandemic. Eur Cardiol 15:e16. https://doi.org/10.15420/ecr.2020.11

Kwong JC, Schwartz KL, Campitelli MA, Chung H, Crowcroft NS, Karnauchow T, Katz K, Ko DT, McGeer AJ, McNally D, Richardson DC, Rosella LC, Simor A, Smieja M, Zahariadis G, Gubbay JB (2018) Acute myocardial infarction after laboratoryconfirmed influenza infection. N Engl J Med 378:345-353. https:// doi.org/10.1056/NEJMoa1702090

Lau JT, Griffiths S, Choi KC, Tsui HY (2010) Avoidance behaviors and negative psychological responses in the general population in the initial stage of the H1N1 pandemic in Hong Kong. BMC Infect Dis 10:139. https://doi.org/10.1186/1471-2334-10-139

Mahmud E, Dauerman HL, Welt FG, Messenger JC, Rao SV, Grines C, Mattu A, Kirtane AJ, Jauhar R, Meraj P, Rokos IC, Rumsfeld JS, Henry TD (2020a) Management of acute myocardial infarction during the COVID-19 pandemic: a position statement from the Society for Cardiovascular Angiography and Interventions (SCAI), the American College of Cardiology (ACC), and the American College of Emergency Physicians (ACEP). J Am Coll Cardiol 76: 1375-1384. https://doi.org/10.1016/j.jacc.2020.04.039

Mahmud N, Hubbard RA, Kaplan DE, Serper M (2020b) Declining cirrhosis hospitalizations in the wake of the COVID-19 pandemic: a National Cohort Study. Gastroenterology 159:1134-1136. https:// doi.org/10.1053/j.gastro.2020.05.005

Martinez-Ferran M, de la Guía-Galipienso F, Sanchis-Gomar F, ParejaGaleano H (2020) Metabolic impacts of confinement during the COVID-19 pandemic due to modified diet and physical activity habits. Nutrients 12:1549. https://doi.org/10.3390/nu12061549

Metzler B, Siostrzonek P, Binder RK, Bauer A, Reinstadler SJ (2020) Decline of acute coronary syndrome admissions in Austria since the outbreak of COVID-19: the pandemic response causes cardiac collateral damage. Eur Heart J 41:1852-1853. https://doi.org/10.1093/ eurheartj/ehaa314

Moroni F, Gramegna M, Ajello S, Beneduce A, Baldetti L, Vilca LM, Cappelletti A, Scandroglio AM, Azzalini L (2020) Collateral damage: medical care avoidance behavior among patients with acute coronary syndrome during the COVID-19 pandemic. JACC Case Rep 2:1620-1624. https://doi.org/10.1016/j.jaccas.2020.04.010

Muhammad S, Long X, Salman M (2020) COVID-19 pandemic and environmental pollution: a blessing in disguise? Sci Total Environ 728:138820. https://doi.org/10.1016/j.scitotenv.2020.138820

National Statistics Office (2019) Key figures for Malta - visuals and words - 2019 edition. https://nso.gov.mt/en/nso/Media/SalientPoints-of-Publications/Pages/Key-Figures-for-Malta\%2D\%2D2019.aspx. Accessed 15 Jun 2020
Nguyen HL, Saczynski JS, Gore JM, Goldberg RJ (2010) Age and sex differences in duration of pre-hospital delay in patients with acute myocardial infarction: a systematic review. Circ Cardiovasc Qual Outcomes 3:82-92. https://doi.org/10.1161/CIRCOUTCOMES. 109.884361

Onest (2020) Malta's Reaction Tracker - COVID-19 Malta. Malta COVID-19 sentiment tracker. https://covid19malta.com/maltasreaction-tracker/. Accessed 9 May 2020

Pessoa-Amorim G, Camm CF, Gajendragadkar P, De Maria GL, Arsac $\mathrm{C}$, Laroche C, Zamorano JL, Weidinger F, Achenbach S, Maggioni AP, Gale CP, Poppas A, Casadei B (2020) Admission of patients with STEMI since the outbreak of the COVID-19 pandemic. A survey by the European Society of Cardiology. Eur Heart J Qual Care Clin Outcomes 6:210-216. https://doi.org/10.1093/ehjqcco/ qcaa046

Rodríguez-Leor O, Cid-Álvarez B, Ojeda S, Martín-Moreiras J, Ramón Rumoroso J, López-Palop R, Serrador A, Cequier Á, Romaguera R, Cruz I, de Prado AP, Moreno R (2020) Impacto de la pandemia de COVID- 19 sobre la actividad asistencial en cardiología intervencionista en España. REC Interv Cardiol 2:82-89. https:// doi.org/10.24875/RECIC.M20000120

Saad L (2020) Americans Worry Doctor Visits Raise COVID-19 Risk. https://news.gallup.com/poll/307640/americans-worry-doctorvisits-raise-covid-risk.aspx. Accessed 9 May 2020

Sammut M (2011) Acute cardiac coronary events and stress generated at a population level. Dissertation, University of Malta

Solomon MD, McNulty EJ, Rana JS, Leong TK, Lee C, Sung SH, Ambrosy AP, Sidney S, Go AS (2020) The Covid-19 pandemic and the incidence of acute myocardial infarction. N Engl J Med 383:691-693. https://doi.org/10.1056/NEJMc2015630

Tavazzi G, Pellegrini C, Maurelli M, Belliato M, Sciutti F, Bottazzi A, Sepe PA, Resasco T, Camporotondo R, Bruno R, Baldanti F, Paolucci S, Pelenghi S, Iotti GA, Mojoli F, Arbustini E (2020) Myocardial localization of coronavirus in COVID-19 cardiogenic shock. Eur J Heart Fail 22:911-915. https://doi.org/10.1002/ejhf. 1828

Tsioufis K, Chrysohoou C, Kariori M, Leontsinis I, Dalakouras I, Papanikolaou A, Charalambus G, Sambatakou H, Siassos G, Panagiotakos D, Tousoulis D (2020) The mystery of "missing" visits in an emergency cardiology department, in the era of COVID-19.; a time-series analysis in a tertiary Greek general hospital. Clin Res Cardiol 109:1483-1489. https://doi.org/10.1007/ s00392-020-01682-1

Walsh JC, Lynch M, Murphy AW, Daly K (2004) Factors influencing the decision to seek treatment for symptoms of acute myocardial infarction: an evaluation of the self-regulatory model of illness behaviour. J Psychosom Res 56:67-73. https://doi.org/10.1016/S00223999(03)00082-5

Welt FGP, Shah PB, Aronow HD, Bortnick AE, Henry TD, Sherwood MW, Young MN, Davidson LJ, Kadavath S, Mahmud E, Kirtane AJ (2020) Catheterization laboratory considerations during the coronavirus (COVID-19) pandemic: from the ACC's interventional council and SCAI. J Am Coll Cardiol 75:2372-2375. https://doi. org/10.1016/j.jacc.2020.03.021

Worldometer (2020) Coronavirus update (Live): Worldometer. https:// www.worldometers.info/coronavirus/. Accessed 15 Jun 2020

Zhou F, Yu T, Du R, Fan G, Liu Y, Liu Z, Xiang J, Wang Y, Song B, Gu X, Guan L, Wei Y, Li H, Wu X, Xu J, Tu S, Zhang Y, Chen H, Cao B (2020) Clinical course and risk factors for mortality of adult inpatients with COVID-19 in Wuhan, China: a retrospective cohort study. Lancet 395:1054-1062. https://doi.org/10.1016/S01406736(20)30566-3

Publisher's note Springer Nature remains neutral with regard to jurisdictional claims in published maps and institutional affiliations. 